\title{
ARTÍ́CULO \\ EL ENFOQUE MULTIMODAL DEL PROCESO DE ALFABETIZACIÓN
}

\author{
JAVIER GONZÁLEZ GARCÍA ${ }^{*}$ \\ https://orcid.org/0000-0001-5116-9728
}

RESUMEN:Elartículo se centra en una revisión del concepto de alfabetización multimodal, analizando este concepto de forma operativa. Se parte de sus posibilidades de uso, y su necesidad de cohesión a la hora de aplicar sus estrategias. Se detecta una retórica propia del diseño de los textos a partir de las nuevas aplicaciones en el uso de las nuevas tecnologías. A continuación se insertan varios ejemplos: una actividad que ejemplifica un proceso de alfabetización multimodal, dos actividades de alfabetización mediática y ejemplos en varios países europeos de la alfabetización multimodal a través de videojuegos. Finalmente, observamos cómo estas propuestas de alfabetización están conformadas por procesos de análisis, reflexión y producción documental que acogen toda una diversidad multimodal de lenguajes que producen procesos multiculturales en las personas que participan en los mismos.

Palabras clave: Multimodalidad; Retórica; Semiótica social; Elaboración de textos; Alfabetización temprana.

\section{O PROCESSO DE ALFABETIZAĈ̣̃O ABORDAGEM MULTIMODAL}

RESUMO: $O$ artigo enfoca uma revisão do conceito de alfabetização multimodal, analisando esse conceito operacionalmente. Baseia-se em suas possibilidades de uso e em sua necessidade de coesão ao aplicar seus princípios. Uma característica retórica do design dos textos é detectada a partir das novas aplicações no uso de novas tecnologias. Por fim, insere-se um exemplo de atividade que exemplifica um processo de alfabetização multimodal. Conclui-se que a natureza dessa proposta de alfabetização é moldada pelos processos de análise, reflexão e produção documental que englobam a diversidade multimodal das línguas e a diversidade multicultural das pessoas que delas participam.

Palavras chave: A multimodalidade; Retórica; Semiótica social; Escrever textos; Alfabetização precoce.

\footnotetext{
${ }^{1}$ Universidad de Guanajuato, División de Arquitectura, Arte y Diseño. Música y Artes escénicas, Colonia Marfil, México.

"Doctor en Ciencias de la Educación (Universidad de Burgos), Master en Comunicación y Educación (Universidad Autónoma de Barcelona), Licenciado en Psicología (Universidad de Deusto). Profesor investigador a tiempo completo en Universidad de Guanajuato (México). División de Arquitectura, Arte y Diseño. Música y Artes escénicas. Departamento de Música e Artes Cênicas. Membro do Sistema Nacional de Pesquisadores do México. E-mail: <jr2000x@yahoo.es> e <jr2000x@gmail.com>.
} 


\section{MULTIMODAL APPROACH TO LITERACY PROCESS}

ABSTRACT: The article focuses on a review of the concept of multimodal literacy, analyzing this concept operationally. It is based on its possibilities of use, and its need for cohesion when applying its strategies. A rhetoric characteristic of the design of the texts is detected from the new applications in the use of new technologies. Below are several examples: an activity that exemplifies a multimodal literacy process, two media literacy activities and examples in several European countries of multimodal literacy through video games. Finally, we observe how these literacy proposals are made up of processes of analysis, reflection and documentary production that embrace a multimodal diversity of languages that produce multicultural processes in the people who participate in them.

Keywords: Multimodality; Rhetoric; Social semiotics; Text-making; Early literacy.

\section{INTRODUCCIÓN}

La capacidad de los niños para moverse con destreza entre las nuevas modas y medios de comunicación es un reflejo y síntoma de los cambios globales en la elaboración de significados, además de llevar a una revisión y redefinición a posibles salidas prácticas de la alfabetización. Esto marca un cambio y un desarrollo en cómo el texto se entiende y se comprende. Desde hace mucho tiempo dentro del aula, los textos se asocian principalmente con la escritura, como representación del discurso trascrito. Se presenta como si fueran géneros instalados y formas fijas. Durante los últimos diez años, la investigación multimodal ha desafiado a las definiciones unimodales, y ha mostrado que el aprendizaje de la alfabetización exige la comprensión de la compleja interrelación entre el material escrito y gráfico, unido a los modos corporales de construcción de significado (Bearne, 2009). Los avances tecnológicos y el desarrollo de la comunicación global han introducido nuevos géneros, formas y medios de comunicación, desafiando el punto de vista del texto como algo fijo y estático, y no susceptible de cambio por parte de los responsables individuales del texto. Considerando que en las aulas se han adoptado con frecuencia una prudente, incluso una actitud antagónica a las nuevas formas y modos de elaboración de significado, para los niños pequeños son menores los límites establecidos permitiéndolos adaptarse a cambiar los paisajes textuales, hacia maneras creativas, innovadoras y multimodales. Sus textos pueden incluir escritura, imágenes visuales y objetos, de dos o tres dimensiones, que podrían ser de papel, diseñados en la pantalla, o en los medios de comunicación, y que podrían implicar efectos 
visuales, musicales o cinestésicos, y que tal vez sean incorporados a la lengua, el sonido, el gesto, o la acción (LANCASTER Y ROWE, 2009). Estos cambios plantean importantes problemas teóricos, pedagógicos y metodológicos para los investigadores y los profesionales. La elaboración de datos de manera que facilite el análisis de múltiples sistemas de signos, conservando la capacidad de administración, requiere delicadeza en su propuesta y experiencia en el uso de técnicas digitales y software, para facilitar la investigación destinada a la transformación de la alfabetización en las aulas del siglo XXI. Carey Jewitt y Gunther Kress coordinaron en 2003 la primera colección de artículos sobre la alfabetización multimodal.

Diferentes investigadores han estudiado el discurso en las aulas de clase desde un enfoque multimodal (LEMKE, 1998; KRESS, 2005; JEWIT'T, 2008 Y STEIN, 2008), preguntándose por los diversos tipos de lenguajes usados en las clases y sus aspectos retóricos, haciendo referencia al lenguaje oral, escrito, gestual y corporal; estos estudios realizan aportes específicos desde el lenguaje oral y escrito y los vinculan con otros recursos utilizados por docentes y estudiantes en las aulas de clase, entre ellos las TIC, los libros de texto, y las imágenes entre otros etc. Es así, como el propio salón de clase puede ser visto como un espacio multimodal por su disposición espacial, el mobiliario, los recursos audiovisuales, y las herramientas y artefactos de que dispone, además, de los diversos discursos comunicativos que se articulan en torno al conocimiento. Kress (2005), propone que la comunicación ocurre a través de diferentes modos de significación como el texto, imágenes, gráficos, sonido, música, etc. de manera simultánea. Por esta razón, para entender el significado de un acto comunicativo hay que tener en cuenta todos los modos utilizados en él y no se pueden estudiar de forma aislada, por cuanto están estrechamente relacionados entre sí. El concepto de modo es definido por el autor como un recurso semiótico social y cultural a partir del cual se construyen significados. De este modo, la escritura, el diseño, la música, los gestos, las palabras, las imágenes, y los objetos en 3D, son ejemplos visibles de los diversos modos utilizados para la representación y la comunicación. Estos modos trabajados con diferentes propósitos e intenciones comunicativas y pedagógicas, conllevan efectos significativos entre el enseñar y el aprender en las aulas de clase contemporáneas, ya que los estudiantes ponen en juego múltiples recursos semióticos para plasmar significados. Desde esta perspectiva, un enfoque basado en la enseñanza multimodal deja por fuera la enseñanza "tradicional" y lo que habitualmente ha significado el lenguaje: simplemente leer y escribir. 
Kress (2005) ha manifestado que los nuevos medios de información y comunicación presentan unas facilidades que difieren de medios como los libros en tanto disponen de mayores potencialidades para la acción por parte de lectores, escritores, y creadores de texto de una forma interactiva, lo que implica que los sujetos pueden interactuar, y participar de los procesos de elaboración y construcción del conocimiento. La importancia del concepto de multimodalidad al momento de pensar las prácticas de enseñanza en los contextos de aprendizaje escolar, radica en el surgimiento de nuevos modos de representación y comunicación que significan un cambio de paradigma en la alfabetización. Las transformaciones surgidas de una enseñanza "tradicional", a las prácticas de enseñanza multimodal, han dado señales de un cambio sustancial en el tema de la alfabetización "tradicional", dando paso a una nueva alfabetización que ve en las imágenes, los gestos, la música, los movimientos, la animación y otros modos de representación formas diferentes de plasmar y acceder al conocimiento. Una muestra de ello, es la facilidad con que los estudiantes pueden dibujar, pintar, cantar y bailar, además de producir sus propias películas digitales, dominar juegos complejos de computador y participar en la creación de sitios web interactivos, lo cual implica que la alfabetización hoy va más allá del conocimiento y la codificación y decodificación de letras. En las nuevas formas de alfabetizaciones, las imágenes y los sonidos ocupan un lugar protagónico, con el mismo nivel jerárquico que tiene el texto alfabético. La adquisición de habilidades para la comprender textos icónicos y sonidos, cobra la misma relevancia que hasta hace poco tenía el texto alfabético. Con el mejoramiento de los equipos y programas para procesar gráficos, la presencia de las imágenes se ha vuelto cada vez más recurrente en los textos digitales, y ha obligado a los lectores a adquirir habilidades para interpretar y contextualizar la información presente en estos nuevos formatos. Las nuevas alfabetizaciones buscan aprovechar las características multimodales y flexibles que proveen los hipermedios para generar habilidades de pensamiento, fomentar aprendizaje, estimular la capacidad del estudiante para generar preguntas críticas.

El concepto de convergencia mediática está basado en las nuevas posibilidades de acción y participación de los usuarios que ha abierto la digitalización de los medios. La convergencia, pues, anuncia la coexistencia de los nuevos medios digitales con el auge de una cultura participativa, protagonizada por comunidades de usuarios de una actividad casi frenética, Múltiples modos de acceder a los contenidos 
mediáticos Cultura participativa de abajo hacia arriba. Este autor se ocupa de fenómenos de transmediación -es decir, de contenidos y relatos que atraviesan diferentes soportes. Excelente interrogación sobre los nuevos fenómenos que surgen con el desplazamiento del antiguo paradigma de la comunicación de masas y el inicio de la cultura multimedia.

Estos conceptos afectan a una nueva visión de cómo entender la alfabetización, y las implicaciones que esto puede tener. Revisamos líneas abiertas que trabajan aspectos concretos de la multimodalidad en las aulas.

Wohlwend y Mavers (2009) exploran el impacto de las nuevas tecnologías en los primeros años del aula, aunque desde perspectivas muy diferentes. Este trabajo muestra cómo los niños pueden usar nuevas tecnologías, como teléfonos móviles y videojuegos, con el formato de hojas impresas, que dan a las nuevas tecnologías y a las alfabetizaciones una repetición mixta. Mavers muestra la utilidad del uso de tecnologías simples, tales como pizarrones individuales. Estos pueden proporcionar magníficos espacios para que los niños desarrollen ideas e hipótesis y los registren como textos efímeros, importantes por el momento.

Pahl (2009) examina la relación entre la conversación y el texto. Explora la materialidad de los textos, y muestra como la conversación puede imaginativamente estirar y transformar el material y el significado textual más allá de las estructuras inmediatas del aula.

Flewitt (2009) utiliza descripciones y análisis multimodales para abordar las cuestiones de la diferencia. Flewitt señala la evidencia de un estudio de niños con necesidades educativas especiales. Estos autores destacan la importancia de las interacciones encarnadas entre adultos y niños, y reconocen la idiosincrasia, y los significados multimodales que caracterizan a sus eventos de alfabetización.

Albers et al. (2009) destacan el papel que desempeñan las imágenes visuales en la producción de textos infantiles. Utilizan una lectura esquemática de los textos visuales para evaluar las actitudes de los niños de acuerdo a su género, analizando las imágenes de las niñas producidas por niños, y las de los niños por las niñas.

Bearne (2009) argumenta que la complejidad de los textos multimodales no está bien respaldada por los sistemas desarrollados para el lenguaje oral y escrito. Su trabajo presenta un marco de referencia para describir la interrelación de los elementos de la imagen, el lenguaje, el sonido, la mirada, y los movimientos de los niños en la producción de textos multimodales. Ella sugiere cómo un marco multimodal de este tipo podría ser ampliado para incorporar la evaluación. En este artículo se analiza a profundidad su propuesta. 


\section{MULTIMODALIDAD, ANALFABETISMO Y TEXTOS: UN DISCURSO NUEVO}

Con la mayor disponibilidad y accesibilidad de la tecnología digital, la alfabetización ha dado un giro espacial. La pantalla tiene un lugar central en las comunicaciones públicas y cada vez más en los centros educativos, cambiando las formas en que se entiende la lectura y la escritura. La lectura en pantalla significa usar diferentes y variados medios, vías y procesos de lectura en forma de impresión continua (HOLSANOVA Y HOLMQVIST, 2006; KRESS, 2003A). Ahora escribir no sólo implica un elemento visual, un dibujo, tal vez de variados tamaños, formas y colores de letra y fuentes, también el diseño de la página no va a ser secuencial en la misma forma que el texto escrito continuo. Además, los textos de pantalla, a veces incluyendo la impresión y la imagen, están a menudo acompañados de efectos sonoros y visuales. Los avances tecnológicos también han contribuido a un aumento en los libros de figuras complejas para todas las edades, así como a tener una profunda influencia en el diseño de libros de información (MOSS, 2003). El material que prolifera en lo social y textual en la pantalla y los libros, demanda aportaciones y cambios en las teorías de la alfabetización. La organización espacial de los materiales y las ideas significan una forma diferente de entender cómo están construidos los textos y mediados socialmente. El cambio de la página a la pantalla significa mirar "más allá de la lingüistica" (JEWITT, 2005, p. 315) a la semiótica: a partir de una teoría del lenguaje que tenga en cuenta los diferentes componentes del significado. El semiólogo Halliday (1978) uno de los que tienen mayores influencias en las teorías actuales de la multimodalidad, propone tres elementos de comunicación que funcionan de forma simultánea para obtener significado: ideacional, interpersonal y textual. El componente ideacional implica decisiones acerca de las relaciones interpersonales (audiencia / lectores) de los componentes, y éstos se llevan a cabo en forma de texto, que en último término comunica ideas e intenciones de manera coherente. Así es que el significado centra el enfoque adoptado para el oyente / lector / observador e influye en la estructura del texto. Desde que el elemento ideacional y el interpersonal son los invisibles, o elementos implícitos de la comunicación, la forma del texto en sí, su gramática, comprende el significado a través de la representación de patrones. Al ir más allá, pero incorporando gramática de la oración en su teoría semiótica de la lengua, Halliday (1985) ha influido en la teoría multimodal, ya que toma en cuenta otros elementos no lingüísticos 
de comunicación, como gesto, movimiento, imagen, música, sonido y color junto con la lengua escrita y hablada (COPE Y KALANTZIS, 2000; MACKEN, 2004; MARTINEC Y SALWAY, 2005; KRESS Y VAN LEEUWEN, 2006). Para Halliday, la gramática de cualquier expresión, cualquier presentación, cualquier texto, describe los patrones que hacen que sea comprensible para los miembros de la cultura en la que se ha gestado y recibido.

La sintaxis describe la gramática de la oración: la forma en que cualquier comunidad lingüística espera una oración para que ésta sea el modelo de sentido y referencia para esa comunidad. De forma similar los textos gramaticales representan las expectativas en que algunos textos se estructurarán de acuerdo a los convenios desarrollados. Sin embargo la teoría semiótica también incluye la noción de intencionalidad. Mientras que la gramática de los textos puede ser culturalmente desarrollada, mediada y mantenida, todavía existe la posibilidad de aplicarla y contextualizarla para cada organismo. Esta posición puede parecer paradójica, pero encaja bien con la opinión de Bourdieu de las prácticas sociales como "improvisaciones reguladas" (BOURDIEU, 1977, p. 78). Lejos de que la gramática sea un conjunto fijo de normas, la noción de los patrones de representación permite la flexibilidad, la transformación y la creatividad. El centro de la multimodalidad es el concepto de diseño, de la intencionalidad (KRESS, 2003B; KRESS Y VAN LEEUWEN, 2006), que se introduce a través de una dinámica haciendo, hincapié tanto en las relaciones sociales de cualquier acto comunicativo y las posibilidades de transformación de cómo están construidos los textos. Un elemento esencial es el análisis crítico reflexivo de los textos y "los contextos de la cultura y la situación en la que parece trabajar" (COPE Y KALANTZIS, 2000, p. 24). Multimodalidad, entonces, es parte de una teoría de la alfabetización como esencialmente social (BARTON et al, 1999), y los textos multimodales contribuyen a una ecología cambiante de la alfabetización (MACKEY, 2002), donde la experiencia de los niños con una serie de textos impresos y digitales contribuyen a su potencial para componer y comprender otros textos. En particular, el conocimiento de los niños sobre textos de cultura popular, a menudo en el hogar, les da la base para una comprensión crítica de los textos y los contextos en los que se producen (MARSH, 2004; VÁSQUEZ, 2005). Para dar energía a este potencial crítico en los entornos educativos significa tener un discurso a través del cual describir y analizar textos multimodales (BEARNE 2003; MACKEN, 2004). Esto es fácil decirlo, pero tal discurso tiene que ser por un 
lado lo suficientemente flexible para atender a los modos semióticos diferentes, y por otro tiene que ser capaz de describir tanto un texto especializado como una novela, así como la elevada dispersión de un texto como el de una película. Sin embargo, o quizás debido a la necesidad de un enfoque global, el desarrollo de un marco analítico está presionando sobre todo porque en muchos ámbitos de la educación, al menos los que conciernen a la alfabetización, se espera que los alumnos produzcan textos multimodales.

\section{POSIBILIDADES DE USO Y COHESIÓN}

La ubicuidad de la pantalla y su influencia en las definiciones y la comprensión de la alfabetización no pueden ser subestimadas. Sin embargo, su posición dominante, tiende a oscurecer el hecho de que muchos textos multimodales no se basen en la pantalla. Un texto multimodal se crea con la combinación de: imagen, sonido (incluyendo el habla y la música), el gesto y el movimiento, y la escritura o impresión, ya sea comunicada a través de un papel o de una pantalla, reuniones cara a cara, el espacio donde se desempeña. Esto hace que la empresa de absorber el texto multimodal en la alfabetización sea muy demandante. Tal vez la «alfabetización» no es un término adecuado para describir los textos, contextos y prácticas del siglo XXI, ya que se privilegia lo escrito sobre otras formas de comunicación (BEARNE, 2003, 2005; KRESS, 2003B). En el paisaje cambiante de texto (CARRINGTON, 2005), puede ser más exacto utilizar "texto" para describir la combinación de los distintos modos de representación de la palabra y el sonido: escritura, imagen, gesto, con los distintos medios de comunicación: libros, revistas, equipo pantalla, vídeo, cine, radio. Es importante destacar que los textos multimodales trabajan a través de la combinación y la interrelación de los modos en que se entrelazan para hacer diferentes tipos de texto.

Si el lenguaje y la alfabetización sólo cargan parte del significado de los textos multimodales, entonces es necesario considerar la contribución de todos los elementos de un texto. "Si un mensaje es difundido a través de los diferentes modos, ¿cómo funciona cada componente?" (KRESS, 2003B, p. 35). ¿'Tiene una imagen al igual que las palabras que la acompañan? ¿Un gesto simple, el eco de las palabras habladas que ilumina? Estas preguntas son fundamentales para desarrollar una teoría de la educación de la multimodalidad, ya que los niños necesitan estar en condiciones de elegir el modo más elocuente y los medios de comunicación para sus intenciones comunicativas. Buscar 
respuestas implica considerar el uso potencial de los modos y medios de comunicación, algo que permite al autor de un texto qué hacer y qué restricciones operan. La aplicabilidad de los modos y medios de comunicación de la representación depende del tiempo y el espacio. Si bien es posible que vuelva a leer las páginas de una novela a causa del uso del medio (el libro) y el modo (la palabra impresa), no es posible volver a leer o revisar, salvo en la memoria (o en video), los movimientos y gestos de un ballet. Incluso viendo la producción de nuevo, no dará exactamente la misma representación. Los libros permiten una cierta flexibilidad en el momento en que se pueden apreciar, mientras que las producciones de la etapa no lo hacen. Del mismo modo, el espacio necesario para crear los trabajos, harán una diferencia con respecto a cómo se entienden y se valoran: el espacio ocupado por un libro hace que sea muy portátil; a diferencia de un drama o el ballet. Los diferentes tipos de textos tienen sus propios patrones de cohesión que contribuyen a la arquitectura general del texto. Cuando la narrativa depende de la cohesión cronológica, los textos que se representan visualmente o en diagrama dependerán de la cohesión territorial. La cohesión en los textos de la imagen en movimiento es creada a menudo por una variedad de efectos visuales: motivos repetidos, uso de la perspectiva, primeros planos, medios, y trazos largos; opciones de configuración, color, colocación y la intensidad de la luz; los patrones de efectos de sonido y estribillos musicales, y repeticiones a base de los elementos emocionales del texto. Todo esto unido a la cohesión lingüística del diálogo: conectivas, conjuntivas, referencias de pronombre, deixis, sustitución, elipsis y patrones léxicos. En actuaciones de teatro en vivo o en el ballet, el posicionamiento en el escenario y los ritmos de movimiento y los gestos se añaden a los patrones de sonido, color, iluminación y el diálogo que son los que ayudan a que el drama tenga sentido. En los libros de fotografía narrativa, las líneas, los vectores, la dirección de la mirada de los ojos de los personajes, los motivos visuales repetidos, el gesto y la postura, actúan y ejercen como organización espacial de enlace visual para crear la cohesión del texto. Estos elementos estructurales operan junto a los aspectos ideacionales e interpersonales de significado.

Incorporar las TIC en los procesos de alfabetización desde una perspectiva multimodal posibilitan nuevas formas de presentar la información, pasando del modelo verbal a propuestas multisensoriales, donde la imagen el audio y el video aportan elementos icónicos intuitivos y motivadores que exigen del sujeto nuevas habilidades para acceder a la información. El propósito de 
las transformaciones actuales está en agotar todos los esfuerzos para lograr despertar el interés del estudiante por la lectura y la escritura; pues los tiempos modernos exigen el desarrollo de habilidades de comprensión y comunicación. Esto se puede lograr si los estudiantes tienen sólidas bases en ambas habilidades (KURLAND, 2003). Con el auge de las tecnologías de la información y la comunicación, empieza a hablarse de alfabetización digital, un proceso que según Gros y Contreras (2006) está relacionado con la capacidad para buscar, seleccionar, y evaluar información en su contexto, utilizando herramientas que proporcionan las TIC. Entre las características y habilidades que integran el concepto de la alfabetización digital están: la capacidad para identificar información relevante; habilidades para una lectura dinámica y no secuencial, propia de los entornos hipertextuales, la evaluación critica de los contenidos presentes en la red, la selección de la información; y finalmente la utilización adecuada de las herramientas que brindan los entornos digitales. Las nuevas alfabetizaciones requieren de sujetos con habilidades para buscar datos, es, leer e interpretar textos multimodales, dosificar y separar información relevante, de aquella que no lo es. La educación actual debe ofrecer los medios para que los estudiantes adquieran las habilidades necesarias para desempeñarse en un mundo globalizado, en el que la gran cantidad de información disponible en los medios digitales, requiere ser procesada para la producción de aprendizajes significativos. La alfabetización hoy, es más que el procesamiento de datos; también incluye la capacidad para obtener información de manera eficiente, identificar y resolver problemas, y compartir las soluciones con otros, componer mensajes de correo electrónico o el desarrollo de estrategias para redactar y leer hipertextos. Igualmente se espera que los estudiantes adquieran destrezas para adaptarse a los cambios tecnológicos, y responder socialmente a las necesidades e intereses del medio. La alfabetización en los nuevos entornos implica desarrollar habilidades para localizar, sintetizar y criticar la información presentada en múltiples modos (REINKING, 1998; Y HENAO, RAMÍREZ, Y ZAPATA, 2008).

\section{LA RETÓRICA DEL DISEÑO}

Bearne (2003B) revisa la noción de la retórica de diseño, y lo centra en la producción de los textos de los niños, específicamente en los ambientes educativos. Basándose en las funciones del significado de Halliday, utiliza "diseño" para invocar las formas en 
que los significados ideacionales e interpersonales intencionalmente se combinaron para crear textos, asumiendo la parte activa de los niños. Las tendencias actuales de la retórica (KRESS, 2001) ofrecen una perspectiva unificadora teórica entre lo verbal y lo visual, y contribuyen a un esquema para considerar las formas en que se combinan los modos de comunicar el significado. En la retórica hablada, que incluye el uso de gestos, posturas y movimientos, el "argumento" o efecto comunicativo se realiza a través del énfasis, la entonación, el ritmo y la pausa. Se podría decir que todos estos tienen su paralelo en forma escrita y pictórica. En el texto escrito o ilustrado, el énfasis se crea por el tamaño de la imagen, intensidad de la línea, puntuación, fuente, convenciones gráficas como globos de diálogo, o la repetición léxica o visual (MCCLOUD, 1993). En la retórica hablada se toman en cuenta las diferencias en el sonido de efecto comunicativo; el énfasis persuasivo depende de la pausa y los matices de entonación. Las carencias, comparables a los espacios en blanco en la página, o los silencios en la música o la puntuación en el lenguaje impreso, junto con otros elementos como el gesto enfático y la expresión facial, crean el ritmo del texto y así contribuyen a la fuerza del mensaje. En los textos impresos o visuales el uso del espacio, la colocación de imágenes y el texto, y el tamaño de fuente crean el ritmo y la retórica de la página diseñada. Como los fabricantes de álbum de fotos post-modernas han demostrado, determinadas interrupciones juguetonas de la cohesión del texto, y algunas yuxtaposiciones inesperadas, pueden evocar el humor de una manera similar a los juegos de palabras y chistes verbales (LEWIS, 2001; NIKOLAJEVA; SCOTT, 2001). Además, otras teorías semióticas contribuyen al desarrollo de categorías para describir la orquestación (BOURNE; JEWITT, 2003), de diferentes modos. Usando la idea de la retórica, la manera en que la representación tiene forma de comunicación para un público específico (KRESS, 2001), y cómo se desarrollan los elementos ideacionales e interpersonales, siempre es a través de una combinación de modos. Sin embargo, como todos los textos tienen patrones de cohesión, es posible comparar los efectos de determinados elementos comunes de representación y comunicación. La imagen, incluyendo el contenido, tamaño, color, tono, línea, colocando espacio o uso es un capítulo esencial (KRESS; VAN LEEUWEN, 2006; MACKEN, 2004; MARTINEC Y SALWAY, 2005). El idioma (sintaxis y léxico) es otro componente importante, en el marco propuesto basado en Halliday (1978) y Kress (2001) donde las relaciones entre el lenguaje y otros elementos de la comunicación 
multimodal son vistos como una dinámica de interacción. Desde que la multimodalidad va más allá de la palabra escrita, el sonido, la vocalización y el gesto entran en juego. Van Leeuwen (1999) ha señalado que la entonación está relativamente descuidada en los estudios de la multimodalidad, y aunque él discute acerca de la calidad de voz y el timbre, parece que el sonido en la multimodalidad está fuera de toda teoría. Sidnell y Stivers (2005) también consideran la función de la entonación, basando su discusión en el diálogo interactivo, que hace hincapié en la interrelación entre la palabra y el gesto. En su análisis de los gestos Norris (2004) establece cuatro categorías diferentes: icónica (a menudo con contenido pictórico imitando el habla de acompañamiento); metafóricas (de nuevo con contenido pictórico, pero la presentación de conceptos abstractos); deíctica (apuntando a los objetos o ideas) y tiempo (movimientos enfáticos de entrada / salida o arriba / abajo) (NORRIS, 2004: 28). Línea que parte del trabajo antropológico de Kendon (1997) y de la psicología cognitiva (MCNEIL, 1992). Más recientemente, Kendon (2004) y Streek (1993) han examinado las relaciones entre el gesto y la palabra, incluido el comportamiento facial como gesto, y Franks y Jewitt (2001) han analizado específicamente el gesto como parte de la orquestación del significado a través de los modos semióticos. Junto a estos elementos de la comunicación multimodal y la representación, Norris (2004) también describe el papel de la cabeza y el movimiento corporal y la postura en la comunicación interactiva, mientras que Happonen (2001), basándose en la teoría de la danza, analiza el movimiento y la postura en textos ilustrados de niños. El punto de vista o la mirada es menos frecuente en los análisis de los modos no verbales, aunque muy importante en cuanto a los aspectos interpersonales de la comunicación multimodal y la representación. En su análisis semiótico de la representación e interpretación de signos gráficos, en niños de dos años de edad, Lancaster (2001) identifica tres funciones de la mirada: la analítica, la interpersonal y la expresiva. Su análisis de la relación entre lo interpersonal y los aspectos expresivos de la mirada es particularmente útil en el examen de los textos conductuales. Streek (1993) visualiza la mirada como un regulador, y lo suma a la función interpersonal y la retórica de la mirada. Sin embargo, él se va más lejos en su sugerencia de que la eliminación de la mirada también es significativa, ya que las señales ordenan los pensamientos antes de comenzar y extender la expresión. Kress y Van Leeuwen (2006) ven la mirada en las imágenes como "una forma visual de la dirección" que invita a una relación entre la imagen y 
el espectador. Ellos distinguen entre una mirada directa (imagen que demanda) y una imagen donde la mirada es dirigida hacia la imagen (imagen ofrecida) subrayando así el papel de la mirada en la toma de una relación directa o indirecta con el espectador. Es claro, entonces, que la teoría semiótica ofrece un amplio margen para proponer un marco que sea capaz de describir los diferentes textos multimodales de los niños. Basándose en estas perspectivas teóricas Bearne (2009) usa las siguientes categorías de análisis:

TABLA 1. Categorías de análisis

Imagen: contenido, tamaño, tono de color, línea, colocación/uso del espacio

Idioma: sintaxis y léxico.

Sonido/vocalización: contenido, énfasis, volumen, entonación vocal, pausa, ritmo

Mirada: dirección de la mirada del comunicador o el carácter de la representación

Movimiento: el gesto y la postura.

Fonte: (Bearne, 2009).

Se aplican estos enfoques conceptuales para considerar el patrón gramatical de tres textos multimodales realizados por niños, y para examinar cómo los niños crean textos coherentes mediante entrelazamientos de distintos modos en una forma específica de texto. Algunos ejemplos: texto con explicación detallada basada en la pantalla, una narrativa hablada y un libro de historias con imágenes, con niños de siete años de edad en las aulas de la asignatura de Inglés, muestran cómo los diferentes modos y medios de comunicación pueden ser más o menos dominantes en la creación de un texto integrado. También ilustran cómo el uso de los diferentes modelos se presta más o menos con el tipo seleccionado de texto. Hay, quizás, una ironía sobre el uso de estos tres ejemplos de los textos de los textos multimodales de los niños, precisamente por cuestiones de aplicabilidad. La página impresa de esta revista, no permite por el color, sonido, movimiento y gesto que los textos producidos por los niños sean apreciados parcialmente a través de la descripción.

\subsection{EJEMPLO: LA PINTURA. UN LIBRO DE IMÁGENES POR GRACE (BEARNE, 2009, P. 173-181)}

Uno de los tres ejemplos que incluye Bearne es el llevado a cabo por Viv Sharpe, que presenta los libros de fotos de Anthony Browne en un proyecto diseñado para introducir a su clase con niños de seis 
años algunos de los diferentes elementos de los textos multimodales. Grace se inspiró en fotografías de Willy mientras creaba su historia de aventuras de Lassy, incluyendo el dispositivo meta ficticio de una mano metiéndose en los marcos del libro. También imita algunos de los otros elementos reconocibles de Browne con sombras y detalles del entorno doméstico como motivos repetidos. La historia de Grace sigue una estructura narrativa familiar: ámbito doméstico con carácter principal; dilema (está lloviendo de forma que Lassy no puede salir en su moto); evento de transformación (entrando en la foto), segundo dilema (atrapada y su tía Kathie no la oye); evento y tercer dilema (explora y encuentra el tesoro de un pirata tenebroso), la resolución (se remonta a través de la imagen); conclusión (casa para el té).

\subsection{ANÁLISIS IMAGEN: CONTENIDOS, TAMAÑO, COLOR, TONO, LA LÍNEA, COLOCANDO I USO DEL ESPACIO}

Grace utiliza un estilo peculiar siempre, especialmente a través de la utilización de la mano que actúa como un dispositivo de cohesión, ya que se introduce desde fuera de los marcos de la narrativa pictórica como un deíctico, indicando características de la acción. En la imagen de la portada - véase la figura 2 y tabla 3 - (1) la mano está ajustando la imagen del bebé (¿Tal vez reflejándose en los cambios de Browne?); En otros puntos hacia la misma Lassy en los momentos clave de la narrativa $(2,4$ y 8), o cuando se coloca en el lado derecho parece invitar al lector a pasar la página (3 y 5). Por último, le dice adiós al lector moviendo las manos (8). Este elemento meta ficticio con humor refleja el tema central de la historia donde Lassy pone la mano en una imagen y luego sube a otro mundo. El uso repetitivo de las sombras también contribuye a la cohesión, que apunta hacia la "nueva" (KRESS; VAN LEEUWEN, 2006) parte de la imagen (2, 3 y 5), excepto en la última página donde la sombre señala hacia el final de la parte escrita de la historia (8). Una vez más, reflejando los rasgos característicos del Browne surrealista, Grace utiliza imágenes en la pared para agregar una atmósfera de la narración. La imagen del buque - La pintura del título - cambios cuando Lassy se sube en la segunda página doble se extiende (5) el clima anteriormente tranquilo en la imagen se convierte en tormenta de lluvia y rayos que rodean a Lassy cuando está de pie en la cubierta. En la tercera página doble Lassy y el lector se encuentran dentro de la foto mirando el mar tormentoso fuera del ojo del huracán (6) y a continuación, a la derecha un torbellino, mostrado por la mano intrusa, sugiere la vida difícil que se desarrolla a bordo del (ahora pirata) barco (7). Además, 
al igual que en los libros de Anthony Browne, el cuadro en la pared en la imagen de la derecha de la primera página doble extendida (3) se duplica en miniatura en la imagen del lado derecho de la tercera extensión (7) recordando a Lassy de donde vino.

TABLA 1. Cubierta y Primera página doble extendida

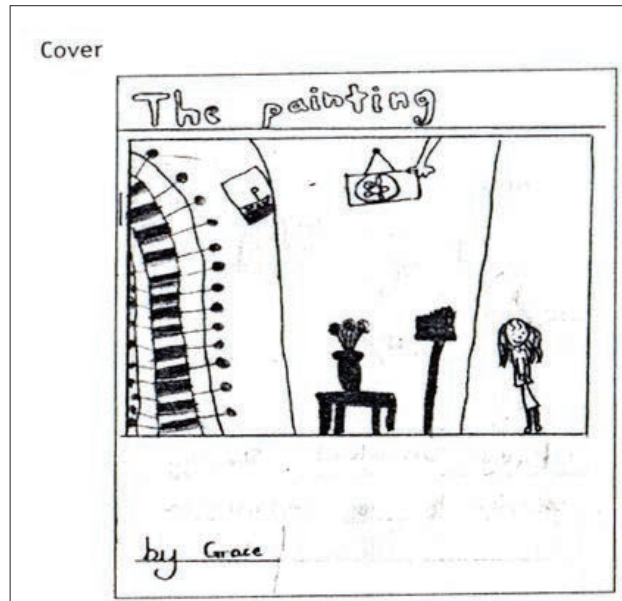

First double page spread
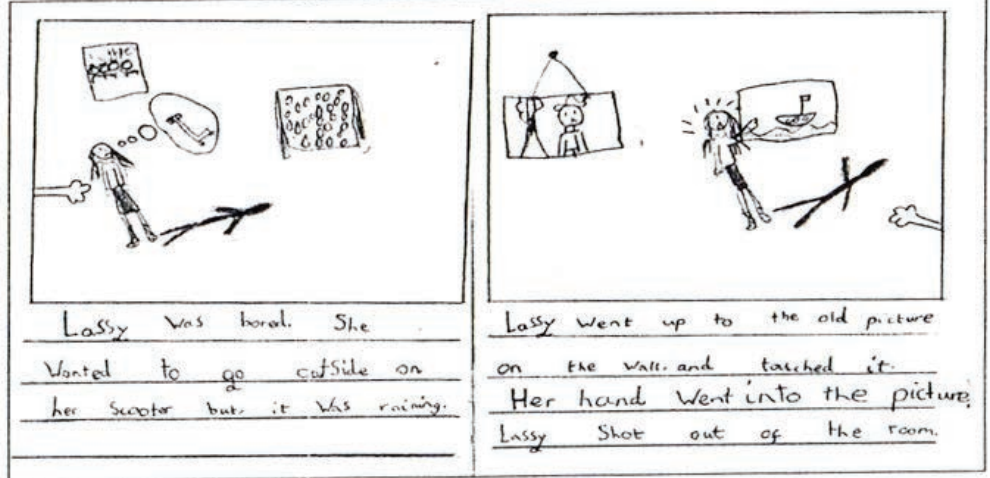

Figure 2 Grace's picturebook

Fonte: (BEARNE, 2009, p. 175).

De acuerdo con la gramática del diseño visual Grace acomoda los elementos de las imágenes en posiciones dadas nuevas, reales e ideales de acuerdo a su interés (KRESS y VAN LEEUWEN, 2006). En la cubierta (1), donde la pintura es el elemento dado del título, la imagen del buque se coloca en la parte superior izquierda y Lassy, que aún no se ha presentado como el personaje principal, está a la derecha en la nueva posición. En el marco izquierdo de la primera 
doble extensión (2) Lassy está en lo que se dio hacia la izquierda reflejando su posición como el sujeto de la oración escrita.

TABLA 2. Segunda y Tercera página doble extendida

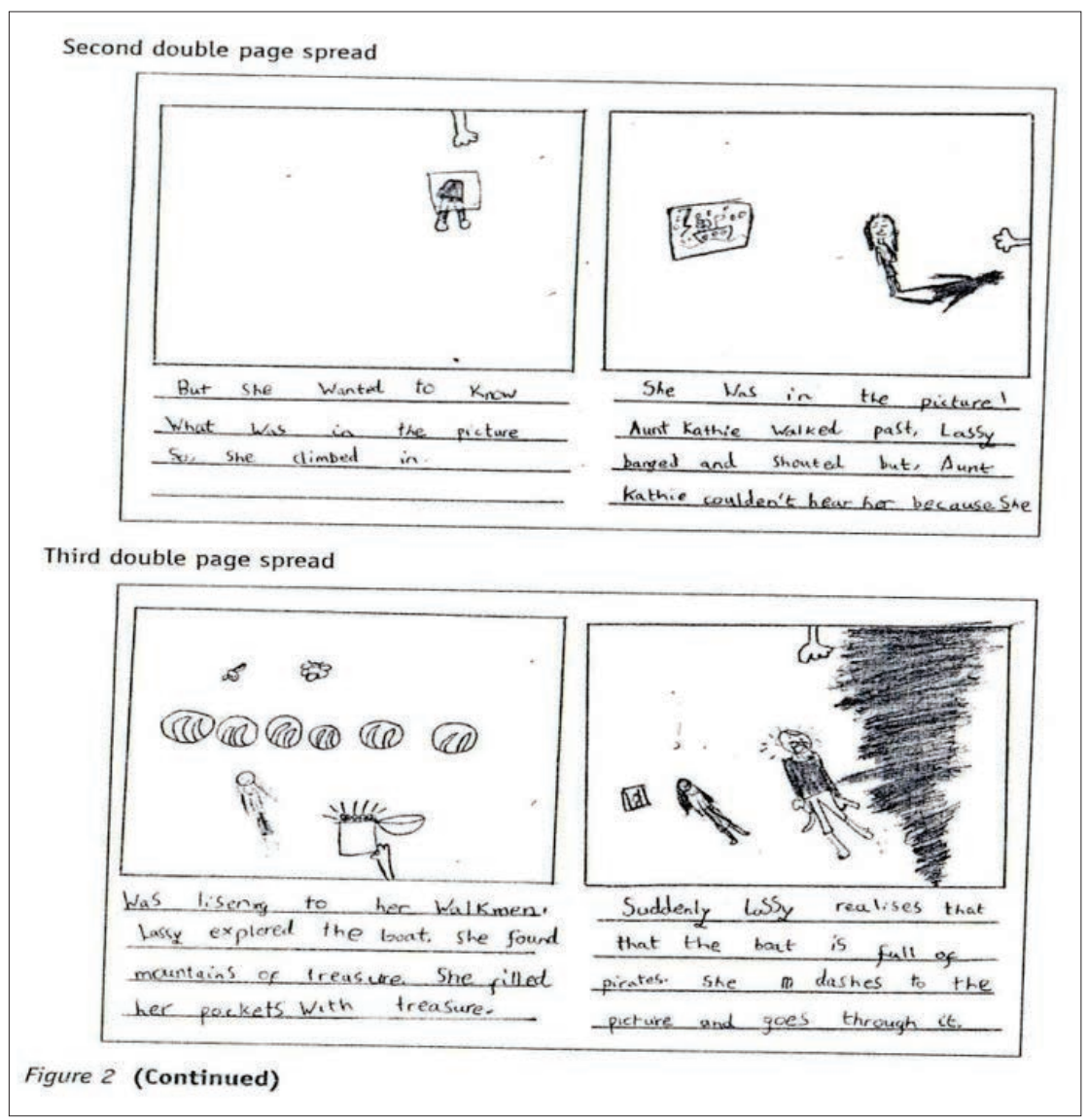

Fonte: (BEARNE, 2009, p. 180).

En la siguiente imagen (3) ella se mueve hacia el centro mientras pone su mano en la imagen - la acción central de la narración. En el marco izquierdo de la segunda doble página (4), Lassy está representada en la nueva posición escalando hacia la imagen, una vez más reflejando su posición en la fase escrita del texto en donde "por lo que subió" termina la frase. En la página siguiente (5) ella está atrapada en la imagen de la izquierda (posición determinada) como en las palabras que dice el lector "Ella estaba en el dibujo". En los últimos tres marcos (6 -8) Lassy una vez más ocupa la posición dada cuando resume su papel como el personaje clave en la historia. La 
mano intrusa aparece a veces desde la posición que indica lo ideal ("de ideas" o "lo que podría ser") (KRESS y VAN LEEUWEN, 2006: 193) como en las páginas donde Lassy está subiendo en la imagen y cuando entra en el torbellino de la parte superior y a la derecha - el nuevo - insinuando los problemas más adelante.

Cubierta posterior

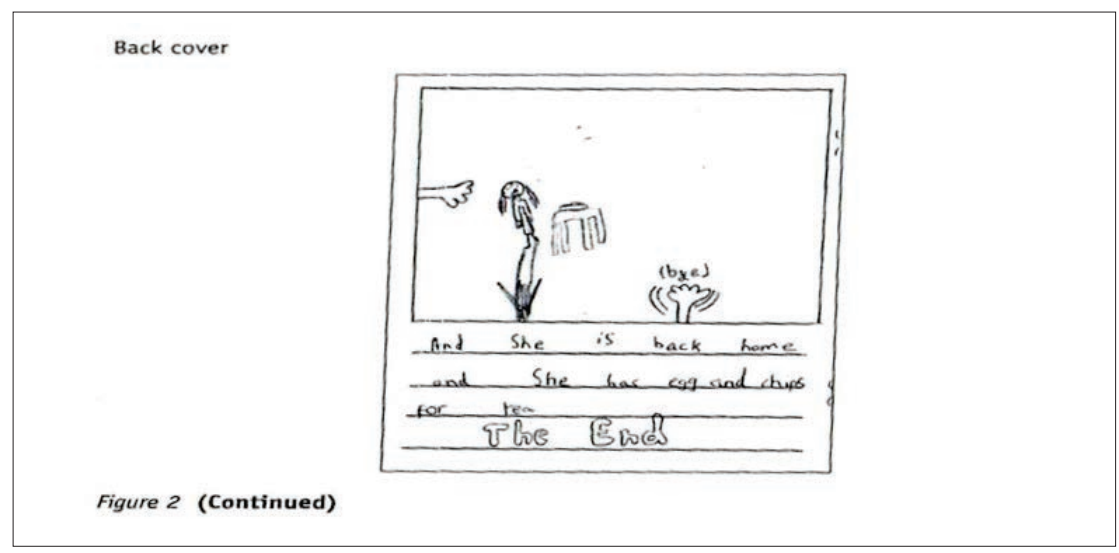

Fonte: (BEARNE, 2009, p. 181).

Grace mantiene una perspectiva a medio intento adecuada a la acción de la historia y con el tamaño adecuado de los personajes y los detalles del fondo a través de su libro. En lugar de utilizar los primeros planos para mejorar su relato ella utiliza detalles selectivos y colores, y como esta es una historia de aventuras sin mucho énfasis en los sentimientos de reflexión, Grace ha elegido acertadamente. La atmósfera es creada a través de detalles domésticos como en la motoneta burbuja de pensamiento, el póster de los Beatles y la lluvia vista a través de la ventana en los primeros dobles extendidos (2); los ojos de buey, el cofre del tesoro (6) y el pirata con aspecto amenazante con su bigote y alfanje (7), y la mesa con la comida de Lassy con huevo y papas fritas en la cubierta posterior (8). Grace es igualmente selectiva respecto al color, usándolo como un motivo de cohesión, por ejemplo, para el mar en la imagen siempre y para y el color de su ropa. Notablemente, en la imagen final en donde Lassy ha vuelto a casa después de su aventura, ella usa diferentes colores. Uno de los aspectos más llamativos del diseño de Grace es el uso del espacio en blanco. Ella desvía la atención hacia los diferentes elementos de los dibujos posicionando cuidadosamente las imágenes que parecen flotar en los espacios de los marcos ordenadas por colores. Este 
dispositivo es el más enfático en el dibujo de Lassy escalando en el dibujo (4). Situado en la parte superior derecha del marco (el ideal / nueva posición que indica lo que está a punto de suceder en el mundo imaginario de la historia) e hizo hincapié en la mano intrusa, siendo este el único elemento en el marco, llamando la atención sobre esta acción como el evento central en la narrativa.

\section{ACTIVIDADES A TRAVÉS DE ALFABETIZACIÓN MEDIÁTICA}

Dentro de las producciones multimodales del alumnado combinan diferentes formatos y lenguajes, principalmente imagen, texto y audio. Además añaden efectos a las diapositivas y a sus transiciones. Estos artefactos culturales siguen todos el mismo patrón, que consiste en una portada con el nombre del ecosistema elegido y una foto; y a continuación diapositivas con una frase y una imagen representativas de la flora y la fauna del mismo. Ponen en juego un conocimiento factual, que se centra en la información como «verdad o hecho»; no se observan como un espacio para la problematización de las cuestiones abordadas ni para la expresión de la voz del alumnado. Realizar estas presentaciones como resultado de las búsquedas llevadas a cabo les ha permitido aprender a identificar las licencias de los contenidos y se han concienciado sobre los derechos de autor, utilizando recursos con licencias Creative Commons, con el fin de poder publicar sus producciones en la Web. Aunque muestran cierta confusión en el tema, principalmente porque les cuesta distinguir entre «poder» (posibilidad-capacidad) y «poder» (aspecto normativo).

Así por ejemplo, Alonso-Ferreiro y Gewerc (2018: 416-418) exponen varias situaciones:

Niño 1: por ejemplo no se pueden usar en un trabajo fotos que... que tienen derechos de autor. Niño 2: están apropiadas. Que no hicimos nosotros.

Niña 1: las que no tienen [derechos de autor] puedes subirlas. $\mathrm{X}$ pudo subir un tráiler de una peli a YouTube.

Otra actividad a destacar es la semana dedicada a la prensa en la escuela. Aprovechando esta celebración, la maestra presentó al alumnado las secciones de un periódico y les mostró prensa digital de diferentes países del mundo. Trabajó principalmente en soporte impreso con diferentes periódicos locales y nacionales, recortando diferentes tipos de textos, como noticias, entrevistas, reportajes o sucesos, sin trabajar con el contenido de los mismos. Además, 
presentó una sección especial del periódico «The Guardian» dedicada a la mujer y eligió un video de la ONG Equals, elaborado para el día internacional de la mujer en 2011. Mientras los niños y niñas observan la pantalla la maestra va comentando cada una de las frases que aparecen, que abordan cuestiones relacionadas con las diferencias de género en el trabajo, la política, la libertad sexual, etc. Cuando acaba el audiovisual la secuencia continúa con la siguiente interacción:

- Maestra: ¿Qué os pareció el vídeo? Se escucha bajito «bien»

- La tutora pregunta de nuevo: ¿cómo pensabais antes y cómo pensáis ahora?

— Un niño (muy bajito): igual

- Maestra: ser sinceros que no pasa nada... ¿pensáis igual que pensabais?

— Niños/as: sí, sí

— Maestra: ¿¿Sí?! ¿Vosotros pensabais que era tanto?

- Algunos mantienen su respuesta: sí, sí

- Otros la cambian: no

- Maestra: no. ¿A qué no?

- Niños/as: no

- Maestra: A que vosotros no entendíais muy bien por qué se celebra esto... qué tontería es esta... porque mi padre y mi madre son iguales...

Y les lanza otra pregunta:

- ¿Vosotros creéis que debe ser celebrado este día?

Dentro de este orden de prácticas dirigidas a trabajar con los medios en el aula, la docente abre un espacio para que este trabajo se extienda más allá del tiempo escolar. Se trata de un grupo creado en la red educativa Edmodo, que es para la gran mayoría (13) su primer perfil en una red social. Utilizan este entorno para compartir sus trabajos, mostrar sus hallazgos o felicitar a los compañeros. Esta plataforma virtual, exclusiva para los actores del aula, es moderada por la profesora que es quien acepta qué contenido se publica, aspecto que el alumnado entiende como natural, «porque tiene que pasar por la profe, lo que hacemos nosotros»

A través de la participación en Edmodo, el alumnado empieza a configurar su identidad digital actuando en la red. Eligen un nombre que los representa, una imagen y aportan en función de sus características. Además, esta red les permite publicar de forma segura en Internet. 


\section{EL USO DE VIDEOJUEGOS}

Los videojuegos se diferencian de los juegos tradicionales en que para su disfrute se hace necesario disponer de tecnología electrónica que sea capaz de hacerlos funcionar: software y hardware, Internet, periféricos de salida o entrada etc. Todo ello amplifica la capacidad de simular el mundo real en universos virtuales, la duración y la complejidad de los retos, el grado de inmersión, la conectividad e interacción con otros jugadores, etc. El desarrollo de videojuegos se conceptualiza mediante un proceso de diseño en el que sus carices inherentes quedan determinados: objetivos, contexto narrativo, interacción, avatares y personalización, carices sonoros y visuales, recompensas. Aunque pudiera interpretarse que las casuísticas serious games y videojuegos educativos fueran más adecuadas para el aprendizaje, consideramos que para el fin de las Alfabetizaciones Multimodales no debe haber un sesgo en la tipología. La razón reside en el cómo y el para qué se utiliza el videojuego, es decir, la actividad pedagógica. Por ejemplo, distínganse un libro de texto diseñado para unos fines pedagógicos predeterminados y otro libro sin fines educativos usado en un club de lectura para facilitar situaciones de aprendizaje (reflexión crítica, habilidades sociales, empatía, etc.). Así, determinamos que el Gaming es la utilización de videojuegos para un propósito indefinido, aun cuando en la propuesta de esta comunicación el propósito es el pedagógico para las Alfabetizaciones Multimodales. El videojuego, como medio, presenta unas características que lo hacen idóneo para determinados aprendizajes.

Un estudio llevado a cabo en escuelas en países europeos, es prueba de buenas prácticas de videojuegos para fines educativos (CRUZ-PALACIOS Y MARZAL, 2017).

En Escocia se utilizó Nintendogs para diversos proyectos: escribir un diario personal en forma de blog contando el avance del juego mientras se consultan otros medios (libros de ficción y sitios web) relacionados con los perros, diseñar una perrera y un hogar para perros de acuerdo a las necesidades señaladas en el videojuego, conectar con la comunidad educativa a través de un blog en el que se contaron las actividades realizadas con el juego, hacer que los alumnos más familiarizados con el videojuegos fueran "profesores" que enseñan cómo funciona el videojuego y acompañan a otros alumnos en su aprendizaje.

En los Países Bajos, se utilizó un videojuego móvil basado en la ciudad de Ámsterdam para una actividad vinculada a la asignatura de historia que combinó blended y mobile learning y competencias 
informacionales, de imagen y de comunicación. Los alumnos se dividieron en dos grupos, uno se desplazaba por la ciudad utilizando el videojuego y un dispositivo móvil para localizar las pruebas a realizar gracias al GPS. Una vez en el lugar, debían contactar con el otro grupo, situado en un aula informática del colegio, a través del dispositivo móvil para solicitar apoyo en la localización de información y resolución de problemas que les ayudaría a completar las actividades propuestas en el videojuego. Después, todo el grupo tuvo que realizar una presentación digital acerca del proyecto y las actividades resueltas. Los resultados mostraron un aumento de la motivación para aprender de manera colaborativa, así como de los conocimientos y del entusiasmo. También se observó que entre los estudiantes había quienes preferían andar por la ciudad como quedarse en el colegio, cuando inicialmente se creyó que todos querrían hacer lo primero. Se consideró que a algunos alumnos les motiva tener todo bajo control, realizar investigaciones en la Web, y resolver problemas.

En Dinamarca, los alumnos usaron The Sims 2 para crear y caracterizar sus personajes, jugar con ellos, utilizar un software de captura de imágenes para grabar momentos de sus partidas, analizar a los personajes y describir los entornos al igual que se hace con los protagonistas de una novela y los lugares en los que ésta se desarrolla, realizar una exposición delante de sus compañeros auxiliándose de medios audiovisuales para narrar la historia que habían construido, y escribir una mini novela protagonizada por su personaje favorito y basada en las partidas que habían jugado. De esta manera, aprendieron conocimientos sobre la personalidad y el comportamiento, cómo analizar y describir personajes y entornos, y practicaron sus habilidades de hablar en público y redacción. También usaron Harry Potter and the Prisoner of Azkaban para que, una vez leído el libro y visto la película homónima, reflexionaran sobre las sensaciones que los dispositivos de reproducción les evocaron; realizar una sinopsis de los capítulos del libro, escenas de la película y partidas del videojuego, y relacionar sus narrativas; y discutir en clase acerca de la experiencia de uso de los videojuegos, los factores de riesgo involucrados, y el hábito de uso propio y con sus padres.

En Francia, los videojuegos fueron utilizados de manera socializadora para combatir el fracaso escolar y el miedo al colegio que algunos alumnos tenían, e incrementar su confianza en sí mismos.

En Austria, se utilizó el videojuego Zoo Tycoon 2 para mejorar las habilidades sociales, de comunicación escrita, conocimientos sobre los animales del videojuego, y las competencias en la gestión económica de los alumnos. 
Más experiencias internacionales se encuentran en el Proyecto "Gamepaddle" en el que se dan a conocer proyectos desarrollados en Alemania, Austria, Italia y Suecia. Los alumnos modelaron una ciudad digital, enseñaron a adultos la relación entre videojuegos y la cultura mediática del siglo XXI, crearon un juego de cartas sobre videojuegos, y reflexionaron sobre el entorno urbano y la ciudadanía. Presentar estas experiencias de Gaming sirve para mostrar cómo los videojuegos han sido utilizados en diversidad de contextos educativos. En todas ellas, se observa cómo los videojuegos son incluidos dentro de una serie de dinámicas pedagógicas como parte de actividades, es decir, constituyen un medio didáctico por el cual se pretende conseguir aprendizajes. Los alumnos se vieron envueltos en dinámicas pedagógicas en las que mejoraron y aprendieron de acuerdo a las cinco dimensiones de las Alfabetizaciones Múltiples: instrumental (acceder y buscar información en diferentes tipos de medios, tecnologías, bases de datos o bibliotecas online), cognitiva (transformar la información en conocimiento haciendo uso de las habilidades de selección, análisis, comparación y aplicación, planteando problemas, analizando e interpretando con significado la información), comunicativa (expresarse y comunicarse a través de múltiples lenguajes y medios tecnológicos, creando documentos textuales, audiovisuales, multimedia e hipertextuales, e interaccionando con otras personas en redes sociales), axiológica (usar la información de manera ética y democrática, de acuerdo a los valores que representan la ciudadanía en el siglo XXI) y emocional (control de los impulsos negativos desarrollando empatía emocional hacia los demás y hacia uno mismo en los espacios virtuales, concienciándose de la experiencia emocional que surge al usar las TIC, y desarrollando una personalidad equilibrada).

Las experiencias de Gaming denotan la gran versatilidad de los videojuegos para la consecución de fines pedagógicos. El Gaming se establece como estrategia didáctica de acuerdo a varias teorías del aprendizaje (conductismo, cognitivismo, constructivismo social, perspectiva sociocultural, conectivismo) y potencialmente desplegable en la diversidad de modalidades educativas (electronic learning, blended learning y mobile learning) para la consecución de unos objetivos de aprendizaje que envuelven desarrollos instrumentales, cognitivos, comunicativos, axiológicos y emocionales. Sin embargo, el Gaming presenta obstáculos que han de tenerse en cuenta para optimizar su efecto educativo: a) el modelo educativo debe ser coherentemente competencial, donde la adquisición de conocimiento 
tenga por objeto asimilarse como una competencia, escenario donde tienen sentido las competencias infocomunicacionales; b) la formación del profesorado es fundamental para una integración eficiente del Gaming en el currículo, y no como una simple "ilustración" o motivación de estímulo; c) el Gaming debe integrarse, pues, en la programación didáctica y diseño curricular para definir unos objetivos didácticos competenciales bien perceptibles por el educando; d) una edición tecnológica que permita al Gaming adquirir las propiedades de Objetos Digitales Educativos.

\section{CONCLUSIONES}

La organización, la elección y la experiencia del texto pueden verse operando dentro de las actividades escolares con fines específicos de aprendizaje. Sin embargo, cuando se trata de instituciones educativas y de situaciones que dan un valor a las producciones de los niños, existen deficiencias importantes en la política y en la práctica (BEARNE, 2009). En cada caso los docentes hacen implicarse a los niños con las características de los textos, y cómo contribuyen estos textos a la comunicación con el público. Todo depende del uso que los propios maestros den a los recursos semióticos de los diferentes modos y medios de comunicación. Un texto de la imagen en movimiento ofrece algo diferente a una novela. Ninguno es mejor que otro, pero cada uno explota la aplicabilidad de modos específicos para hacer el trabajo, que el autor de cada texto quiere que hagan, y estos aspectos deben ser discutidos con los estudiantes (KRESS, 2003, 2005). Para establecer una pedagogía multimodal, hay que describir y evaluar sus progresos (BURKE y HAMMET'T, 2009).

El régimen actual de pruebas se basa en pruebas escritas, y aunque Stein (2003) sostiene que, en términos de lectura, algunos aspectos de la enseñanza y el aprendizaje multimodal se pueden alojar en los acuerdos de las pruebas aplicadas, aún existen barreras a la inclusión de textos de producción multimodal de los estudiantes en la evaluación formal. En parte esto se debe a la falta de un discurso común sobre los textos multimodales. Además, dado que gran parte del trabajo en torno a la multimodalidad se ha asociado con la alfabetización o con la asignatura de la lengua oficial de cada país como materia de enseñanza, las expectativas y prácticas culturales desarrolladas para la evaluación están firmemente arraigadas en los juicios del lenguaje escrito. Hay, actual y afortunadamente, mucho interés en la multimodalidad, pero esto mismo trae problemas, cuando 
los debates se basan en suposiciones sobre si la multimodalidad implica necesariamente pantallas.

La posibilidad futura de un discurso compartido sobre los textos multimodales tendrá que situarse entre las visiones tradicionales de la alfabetización y las seducciones de la tecnología digital (Bearne, 2009). Los seres humanos tienen a su disposición gran variedad de recursos semióticos que se manifiestan de diferentes formas y producen diferentes efectos, por ejemplo "una obra de teatro produce efectos en los participantes, que son diferentes a los efectos producidos por la lectura de una obra de teatro en silencio en la intimidad de una babitación" (STEIN, 2008: 334).

El concepto de multimodalidad es abierto a los significados y a una multiplicidad de modos de comunicación, lo cual resulta enriquecedor cuando se trabaja desde el currículo y la pedagogía de Stein (2008). Si bien, la multimodalidad ha estado presente en los diversos espacios de la cotidianidad, en la actualidad se han configurado nuevas formas multimodales para la enseñanza y el aprendizaje a través de las nuevas tecnologías Kress (2003). Burn y Parker's (2001) han trabajado sobre el tema de medios para la educación y la animación digital, y han indagado, cómo los estudiantes exploran significados a través de los diferentes recursos semióticos disponibles en pantalla y lo que significa esto para el aprendizaje y la alfabetización.

La investigación en el tema de multimodalidad en nuevas tecnologías y el aprendizaje también ha explorado el potencial en el significado y estructura de los textos a través de la vinculación de recursos semióticos, como ocurre con hipertexto y el diseño de hiperenlaces (JEWITT, 2002, 2005; LEMKE, 2002). El significado de las cosas y los acontecimientos es, en definitiva, el resultado de los procesos de interacción de las personas que utilizan dichos lenguajes y marcos culturales para interpretarlos en un momento y lugar determinado (BAUTOSTA, 2007).

Aunque, por otro lado, la investigación evidencia las dificultades que encuentra el profesorado para crear ambientes en los que incorporar los nuevos medios, dificultades que responden en gran medida al conflicto existente entre el discurso vertical característico de la institución escolar, con un currículo oficial centralizado e impuesto desde arriba, y el discurso horizontal idiosincrásico a las tecnologías digitales. La lógica de los medios desafía los tiempos y espacios escolares, choca con los mandatos del currículum y con las condiciones de trabajo del profesorado; que además cuenta con pocos recursos para enfrentarse a la compleja cuestión que supone integrar las tecnologías digitales en la escuela. Como se ha visto, no se trata 
sólo de la presencia de este tipo de actividades, el análisis cualitativo ha posibilitado poner en evidencia las facetas y las limitaciones de su desarrollo. Todas las experiencias tienen su cara y su cruz y requieren continuidad y reflexión por parte del docente para que puedan servir de base al desarrollo profesional, como forma de avanzar hacia mejores condiciones para la educación mediática. Los resultados del trabajo presentado van más allá del conocimiento declarativo recogido por medio de encuestas o entrevistas y evidencian la necesidad de documentar lo no documentado desde la vivencia en la escuela. Además ofrece un acercamiento en profundidad a lo que sucede en el aula día tras día y cómo se integran las estrategias didácticas con los medios en los procesos educativos.

Comprender de una mejor manera las relaciones entre conceptos, las rupturas teóricas, los intereses por trascender las teorías netamente retóricas en la argumentación y las filiaciones entre unas y otras prácticas de enseñanza centradas en la alfabetización multimodal en la escuela, permiten preguntarse: ¿de qué manera construyen los estudiantes el conocimiento cuando escriben utilizando recursos multimodales? ¿Qué factores epistemológicos, sociales, y didácticos influyen en la construcción del conocimiento de los estudiantes cuando escriben utilizando recursos multimodales? ¿Cuál es lugar de la construcción del conocimiento apoyado en recursos multimodales, en la vida cotidiana de los estudiantes? Interrogantes como los aquí planteados fomentan el desarrollo de investigaciones empíricas y teóricas sobre aspectos cognitivos, epistemológicos y didácticos relacionados con la enseñanza o el aprendizaje en la construcción del conocimiento en escenarios de alfabetización multimodal, y contribuyen a la diversificación de propuestas, y análisis sobre cómo se podrían transformar las prácticas en la enseñanza de los objetos de estudio presentados en este texto.

\section{BIBLIOGRAFÍA}

ALONSO-FERREIRO, A., \& GEWERC, A. Alfabetización mediática en la escuela primaria. Estudio de caso en Galicia, 2018.

BARTON, D., HAMILTON, M. Y IVANIC, R. Situated Literacies: Reading and Writing in Context. London: Routledge, 1999.

BEARNE, E. Rethinking Literacy: Communication, Representation and Text. Reading, Literacy and Language, v. 37 n. 3, p. 98-103, 2003.

BEARNE, E. Multimodality, Literacy and texts. Journal of Early Childhood Literacy v.9, n. 2, p. $156-87,2009$. 
BOURDIEU, P. Outline of a Theory of Practice. Cambridge: Cambridge University Press, 1977.

BOURNE, J. Y JEWITT, C. Orchestrating Debate: A Multimodal Analysis of Classroom Interaction. Reading, Literacy and Language v. 37, n. 2, p. 64-72, 2003.

BURKE, A. Y HAMMETT, R. F. Rethinking Assessment in New Literacies. New York: Peter Lang, 2009.

BURN, A. Y PARKER, D. Making your mark: Digital inscription, animation, and a new visual semiotic. Education, Communication and Information, v.1, n. 2, p. 149-154, 2001.

COPE, B., \& KALANTZIS, M. Multiliteracies: Literacy learning and the design of social futures. London: Routledge, 2000.

CRUZ-PALACIOS, E., \& MARZAL GARCÍA-QUISMONDO, M. A. Gaming como medio didáctico para las alfabetizaciones múltiples. Videojuegos en la educación del siglo XXI, 2017.

FLEWITT, J. Multimodal analysis: key uses. Journal of Early Childhood Literacy, v. 9, n. 2, p. $15-47,2009$.

FRANKS, A. Y JEWITT. C. The Meaning of Actions in the Science Classroom. British Educational Research Journal, v. 27, n. 2, p. 201-18, 2001.

GROS, B., Y CONTRERAS, D. La alfabetización digital y el desarrollo de competencias ciudadanas. Revista Iberoamericana de Educación, n. 42, p. 103-125, 2006.

HALLIDAY, M.A.K. Language as a Social Semiotic: The Social Interpretation of Language and Meaning. London: Edward Arnold, 1978.

HAPPONEN, S. Choreography of Characters: Movement and Postures in Illustrated Text for Children. Reading, Literacy and Language, v. 35, n. 3, p. 99-105, 2001.

HENAO, O., RAMÍREZ, D. Y ZAPATA, F. Diseño y experimentación de una propuesta de alfabetización digital para estudiantes de educación básica. En Alcaldía de Medellín (Editor) Agenda de Estudios de Ciudad con énfasis en Medellín. Medellín: Departamento Administrativo de Planeación, p. 155-169, 2008.

HOLSANOVA, J. Y HOLMQVIST, K. Entry points and Reading Paths on Newspaper Spreads: Comparing a Semiotic Analysis with Eye-tracking Measurements. Visual Communication, v. 5, n. 1, p. 65-93, 2006.

JENKINS, H. Convergence culture: la cultura de la convergencia de los medios de comunicación. Barcelona: Paidos, 2008.

JEWIT, C. Multimodal Discourses Across The Curriculum. En: M. Martin-Jones, A. M. de Mejia and N. H. Hornberger (eds), Encyclopedia of Language and Education, 2nd Edition, Discourse and Education, n. 3, p. 357-367, 2008.

JEWITT, C. The move from page to screen: the multimodal reshaping of school English. Journal of Visual Communication, v. 1, n. 2, p. 171-196, 2002. 
JEWITT, C. Multimodality, Reading and Writing for the $21^{\text {st }}$ Century. Discourse, v. 26, n. 3, p. 315-31, 2005.

KENDON, A. Gesture. Annual Review of Anthropology, n. 26, p. 109-28, 1997.

KENDON, A. Gesture: Visible Action as Utterance. Cambridge: Cambridge University Press, 2004.

KRESS, G. Interpretation or Design: From the World Told to The World Shown. En M. Styles and E. Bearne (ed.). Art, Narrative and Childhood. Stoke on Trent: Trentham Books, p. 137-53, 2003A.

KRESS, G. Literacy in the New Media Age. London and New York: Routledge Taylor Francis, 2003B.

KRESS, G. Alfabetismo y multimodalidad. Un marco teórico. En G. Kress, El alfabetismo en la era de los nuevos medios de comunicación. Granada, España: Ediciones Aljibe, p. 49-82, 2005.

KRESS, G. Y VAN LEEUWEN, T. Reading Images: The grammar of Visual Design. London: Routledge, 2006.

KRESS, G., JEWITT, C., BOURNE, J., HARDCASTLE, J., JONES, K., REID; FRANKS, A. London: Routledge Falmer, 2005.

KRESS, G.; JEWITT, C.; OGBORN, J. Y TSATSARELIS, C. Multimodal Teaching and Learning: The rhetoric of the Science Classroom. London: Continuum, 2001.

LANCASTER, L. Staring at the Page: The Funtions of Gaze in a Young Childs Interpretation of Symbolic Forms. Journal of Early Child Childhood Literacy, v. 1, n. 2, p. 131-52, 2001.

MACKEN, M. Interaction with multimodal text: Reflections on Image and Verbiage in Art Express. Visual Communications, v. 3, n. 1, p. 5-26, 2004.

MARTINEC, R.; Y SALWAY, A. A System for Image-Text Relations in New (and Old) Media. Visual Communications, v. 4, n. 3, p. 337-71, 2005.

MAVERS, D. Student text-making as semiotic work. Journal of Early Childhood Literacy, v. 9, n. 2, p. 141-55, 2009.

NORRIS, S. Analyzing Multimodal Interactions: A methodological Framework. New York and London: Routledge, 2004.

PAHL, K. Interactions, intersections and improvisations: Studying the multimodal texts and classroom talk of six to seven year olds. Journal of Early Childhood Literacy, v. 9, n. 2, p. 188-210, 2009.

STEIN, P. Representation, Rights and Recourses: Multimodal Pedagogies in the Language and Literacy Classroom. En: NORTON, B. and TOOHEY, K. (ed.) Critical Pedagogies and Language Learning. Cambridge. Cambridge University Press, p. 95-111, 2003.

STEIN, P. Multimodal Instructional Practices. En: COIRO, J.; KNOBEL, M.; LANKSHEAR, C. y LEU, D. Handbook of Research on New Literacies, New York: Lawrence Erlbaum Associates, p. 871-898, 2008. 
STREEK, J. Gesture as Communication I: Its coordination with Gaze and Speech. Communication Monographs, v. 60, n. 4, p. 275-99, 1999.

VAN LEEUWEN, T. Speech, Music, Sound. London: Palgrave Macmillan, 1999.

Sumisión: 20/03/2017

Aprobación: 09/05/2018

Contacto:

Javier González García

Endereço na Espanha:

Avda. Cantabria $51,2^{\circ}$ F2, Burgos

CP: 09006

Teléfono domicilio: (947) 228285

Endereço no México:

Mineral de Sirena, 300.

Colonia Marfil

CP: 36000

Guanajuato teléfono: (473) 7334043 